\title{
Analysis on Chinese Experience of Macmillan Gap Management
}

\author{
Yang $\mathrm{Li}^{1, \mathrm{a}}, \mathrm{He} \mathrm{Wu}^{1}$, Zeyuan Zhao ${ }^{1}$ \\ ${ }^{1}$ School of Accounting, Jilin University of Finance and Economics, Jilin Province, China \\ a9106283@qq.com
}

Keywords: Small And Medium-Sized Enterprises (Smes); Financing; Management Experience.

\begin{abstract}
SMEs are an important part of China's economy, as well as an important force to promote domestic economic and social development. Especially at present, it is playing a more and more important role in ensuring the appropriate growth of the national economy, optimizing the structure of the economy and alleviating the pressure of employment. From the perspective of world economic development, SMEs of various countries in the development process are exposed to some deep-seated problems, among which the financing difficulty is the key problem of restricting the development of small and medium sized enterprises. Whether in developed countries or in developing countries, government officials, economists and management experts have put it to a strategic height to pay attention to. Compared with developed countries, China's SMEs need to face more difficulties in financing. Therefore, to get rid of this dilemma, we must start from the actual situation in our country. By analyzing and summarizing the management experience of Macmillan Gap in the representative area, this paper puts forward the countermeasures to solve the Macmillan Gap from three angles of enterprise, financial system, government and society. It provides a powerful reference for the financing of SMEs, and it is of great significance on the stable development of SMEs.
\end{abstract}

\section{The Theoretical Foundation and Essence of Macmillan Gap}

In 1929, the worst worldwide economic crisis occurred. In order to deal with this crisis, the British government formed the "Committee on Finance and Industry" headed by Macmillan. The task of this committee was to investigate the economic conditions of several industries. After a large amount of investigations and analyses, Macmillan completed his "Macmillan report", and pointed out that SMEs in Britain had difficulties in financing. Suppliers were not willing to provide funds for SMEs due to various reasons. Thus, financing gap in these enterprises existed universally. This kind of financing gap could also be called as "deficient in credit rationing". After that report, people named these financing gaps, which exist in SMEs' production and operation process, as "Macmillan Gaps".

Essentially, the Macmillan Gap reflects the failure of market regulation on enterprises. In the actual operation of market economy, the "perfect competition" structure cannot exist at all. The pre-conditions of "perfect competition" are extremely strict. So, it cannot exist in the real operational process of economy and markets. Related information is timeliness, and the phenomena of market monopoly are commonly seen. In the field of public appliance, resource allocation is achieved simply through market regulation. Hence, the efficiency of theses industries cannot reach Pareto Optimality, and the market regulation becomes invalid.

\section{Second. The Present Status of Financing Difficulties of SMEs in China.}

Firstly, the short-run operating activities of SMEs block their internal financing channels. Now in our country, the majority of SMEs have relatively small operation and production scales, as well as relatively high staff turnover rate. Most owners of SMEs do not pay attention to the construction of corporate culture. Moreover, SMEs are less stable than large enterprises. Talents in these companies do not have bright prospects for their future development, and they often face the danger of company failure. Therefore, SMEs are less attractive to talents. Lack of talents will cause a series of problems. 
If the company is short of qualified decision makers, the company will be unable to form a good decision-making mechanism, and will be lack of scientific feasibility analyses. Company decisions will be made based on managers' experience, or even on impulse. The shortage of highly qualified technical personnel will cause unreasonable product structure, uneven product quality, and low technological contents in products. The company will also pay less attention to developing new markets. If the company is lack of highly qualified financial management staffs, reasonable financial and managerial systems will not be established, meanwhile, fund utilizing plans will not be made. These shortages will lead to low fund utilization ratio and deterioration of operating conditions. These problems in turn will make the company more difficult to finance from internal channels.

Secondly, the social credit environment in China is not in good condition, which makes the credit financing channels less accessible to enterprises. Nowadays, credit crisis is a common phenomenon in Chinese society. SMEs have increasing difficulties to get credit financing. Especially in recent years, social credit system and people's credit concepts have been distorted. An increasing number of people tend to repudiate or intentionally avoid their debts. Some SMEs refuse to pay their debt publicly, while the banks do not have effective methods to deal with these bad debts. Under that circumstance, banks have to put risk prevention into their first place. Combined with the extremely bad impacts of disposals on non-performing loan cases in last few years, financial institutions now are more reluctant to finance SMEs. Meanwhile, most of these enterprises do not have enough financial and material resources. Usually, a small or medium-sized enterprise only possesses fewer assets and insufficient talents. The overall quality of its staff is relatively low, while the company's ownership structure is unreasonable. Its internal control cannot be completely implemented, and the management system cannot always maintain compliance. These disadvantages lead to the weak competitiveness in the market of this company. Moreover, SMEs often do not have good financial and management systems. Distortion of accounting data and reports are commonly seen. Thus, the credit funds will not flow into these SMEs for their high risks and low incomes. To make things worse, due to the lax enforcement of laws and regulations in China, SMEs almost disregard their credit constructions. Financial institutions then hold biased opinions towards SMEs, and are becoming more reluctant to finance them.

Thirdly, the prudent monetary policy implemented by the government gives rise to the sharply ascending of financing costs. Through the decreasing of liquidity in the banking system, the liquidity of monetary fund in the market can be controlled, and then the adverse effects of currency in inflation market can be reduced. This approach has become an effective way under the environment of steady monetary policy. Loan index becomes lower, which forces these big financial institutions to substantially reduce their external loans. At the same time, banks begin to cooperate with guarantee companies and trust companies to achieve risk diversification and to develop more chargeable projects. In recent years, Central Bank has been raising reserve requirements ratio continuously and increase interest rates, which makes SMEs more difficult to get bank loans, and greatly enhance their financing cost. SMEs have the inherent feature of high risk. Even the company is able to get loans from the banks, the nominal interest rate is usually the 1.3 times of current benchmark interest rates. In addition to professional fee and handling fee which need to be paid to the bank, comprehensive expense ratio for short-term liquidity loans rate can be as high as 10 to 12 percentages. If the loan is ensured through insurance company, additional 2 to 4 percentages of guarantee rate should be counted. If the bank or guarantee company require the enterprise to provide a certain percentage of cash deposit, the cost of capital will be above 18 percentages.

Fourthly, there are not enough regulations to the private credit market, and these informal financing cases may cause crisis. Private credit refers to the loans between citizens, legal persons and other organizations. Financial institutions do not get involved into these loans. Private credit is the inevitable outcome of long-lasting Macmillan Gap and the monopoly of bank in our country. Now the market economy is rather active, SMEs' demands for funds are increasingly growing. These demands stimulate the private credit industry to grow. These private credit companies provide a certain part of funds needed by small and medium-sized enterprise, remedy the limitations of formal financial institutions, promote the circulation of social funds, and propel the rapid development of local 
economy. But since there are no completed laws to regulate them, private credit industry also brings a lot of problems. Firstly, private credit belongs to the grey zone. So far, there are no special laws or regulations to control it. Thus, these credit behaviors often go out of the legal supervisions and management. Secondly, SMEs' increasing demands cause the increasing rate of private credit. Thirdly, the private credit procedure is not standard. Lenders often do not have enough financial security. Economic disputes are commonly seen. This will inevitably increases the risks for both borrowers and lenders.

\section{Three. Chinese Experience of Macmillan Gap Management}

To begin with, the city of Wenzhou in Zhejiang province has following experience on Macmillan Gap management.

Firstly, the appropriate financing channels should be selected. Each enterprise has its own development path, and it has different demands for financing in different periods. In the early stage of its development, the main goal is to develop market, and to manufacture products which meet the demands of market by using its fund. The enterprise does not need a lot of money in that period. The best financing channel in this period is internal financing. When stepping into growth period, the company is competent in its production capacity, sales ability, commercial credit and customer resources. Meanwhile, similar products begin to emerge in the market. The competitive pressure increases, and the competition scope expands. If the goal of this enterprise is to meet consumers' demands for new products, to expand its production scales and to occupy a favorable position in the market, it must increase the scientific and technological contents in its products and try to gain its popularity. These requirements need relatively large amount of money. In this stage, the company can not only depend on internal financing any longer. External financing channels should be explored. A relatively appropriate solution is to place emphasis on credit financing, and to use internal financing as supplements. When companies comes to the mature period, the enterprise management system and financial system are further perfected, and its profit levels also rise. It becomes a high-profile company which has high level of credit rating. The prospect of this enterprise is optimistic. At this time, the company can continue to choose the previous credit financing channels, and try to make a financing strategy which can minimize the comprehensive cost. At present, many small and medium-sized companies in Wenzhou has achieved financing through company listing. It is a very good start.

Secondly, people's concepts should be changed and the discrimination toward company size should be eliminated. Financial institutions should have the awareness of rational allocation of resources, and realize the importance of small and medium-sized companies. They need to recognize that SMEs are their target customers, too; lend money to these enterprises can also get high profits. Financial institutions should focus on company's economic effectiveness, break the old rules which pay overly attention to the scale of a company. A dialectical view toward traditional financing is needed, and the credit resources should be allocated from long-term perspectives. Financial institutions should be realistic, set up financing institutions to serve SMEs exclusively. The government's deployment and policies which are aims to promote the development of SMEs should be implemented strictly.

Thirdly, the diversified financing channels to lead social funds flow should be established. The successful experience of some developed countries tells us that, the risk investment system and the development of off-the-counter market are effective to Macmillan Gap management. The government should broaden the channels for equity capital financing, and change current situation of single financing channel. At the same time, the flexible private capital market can overcome some problems caused by asymmetric information to some extent. SMEs in their initial stages only have small asset scales, so the financial audit to them is difficult to be carried out. External financing is particularly important. The government can standardize private credit markets, such as Angel Investment and venture investment companies, prompt them to play a positive role for the external financing of SMEs in early stage. The government should also encourage SMEs to adopt legal private 
financing. In the early of 2014, the 12th National People's Congress in Zhejiang province deliberated and adopted the "Regulations on Wenzhou Private Financing". This is the first specialized regulation on private financing in China, and it provides legal protection for private financing in Wenzhou.

Furthermore, cities in Guangdong province have following experience on Macmillan Gap management.

Firstly, we need to establish and perfect the financial accounting system and management system, and to maximize the usage of existing funds. Enterprises should attach importance to internal accumulation, and improve their comprehensive strength. The enterprise operators, in particular, need to constantly improve their own comprehensive qualities, and try to master relevant financing and management knowledge. At the same time, all kinds of information in the company should be transparent to ensure the reliable financial data and perfect financial reports; information asymmetry should be reduced, and a standard financial system needs to be established. The management system ought to be standard and unified, which can help banks carry out accurate and scientific credit inquiry. These methods can improve the company's credit rating. At the same time, enterprises should set up their image and strengthen credit consciousness.

Secondly, we need to improve the loan process and its management system; to improve the comprehensive quality of staffs in credit departments. SMEs' demands for funds are "short, frequency, urgent". However, the credit processes in most financial institutions are very complex. These processes discourage a part of SMEs. Financial institutions can assess the credit rating of these SMEs first. For enterprises with good credit records, conditions for loans can be relaxed, and some preferential services can be provided. These conveniences can arouse the enthusiasm of credit financing for SMEs, promote a virtuous circle in credit business. At the same time, credit procedures should be appropriately and reasonably simplified to achieve the result of convenient and benefit to people.

Thirdly, we need to vigorously promote the construction of social credit system, and to perfect the small and medium-sized enterprise information database. The operation and development of enterprises cannot be achieved without the good social environment. The establishment of good social credit system will promote the virtuous development of credit business. In the middle of 2015, the government in Guangdong province issued "Some Suggestions to Innovate and Improve the Investment and Financing Mechanism for SMEs", and puts forward to some methods to establish a "platform for credit information and financing measures". These approaches provide strong supports for the construction of social and enterprise credit system. They are helpful to create a good social credit environment, to eliminate information asymmetry between enterprises and financial institutions, to reduce financial institutions' scruple when lending money to SMEs, and to lead social capital to flow into SMEs. At the same time, the government should promote the construction of credit guarantee system and encourage the development of mutual guarantee institutions. It also needs to promote the development and coordination of policy guarantee, mutual guarantee and commercial guarantee for SMEs. The government and financial institutions ought to work together to help SMEs to walk out of the financing plight.

\section{Four. Analysis of Domestic Treatment Experience}

Through the actual treatment of Macmillan Gap of the above three provinces, we can draw some experience of domestic treatment of Macmillan Gap.

Firstly, a company's self-improvement is conducive to help itself get out of the financial difficulties. Small and medium enterprises in each province should make efforts to strengthen their own corporate culture, clarify the concept of their credit and effectively improve the enterprise's credibility, which make the prospects of both internal financing and external financing clearer. At the same time, they should pass out the information of enterprise development and make their own management status public, so that they can eliminate the information asymmetry between financial institutions. Through their own efforts, the enterprises also continue to improve their economic 
strength. From this perspective, solving the problem of Macmillan Gap requires the enterprises' self-reliance.

Secondly, because of the poor social credit environment, the financial institutions still hold a discriminatory attitude to the small and medium enterprises. Although the government has established an information platform to promote information exchange for the small and medium enterprises, it is not very successful. To solve this problem, the financial institutions should give some opportunities for SMEs, so that the enterprises could prove themselves. In addition, the improvement of social credit environment requires a long time. Therefore, solving the problem of Macmillan Gap will be a lengthy project.

Thirdly, the government's macro-control is of great significance in solving the problem of Macmillan Gap. Both Wenzhou City and Guangdong Province have issued relevant effective regulations to regulate financial markets. The regulations have strongly impacted the illegal financial markets and regulated the order of the financial markets. Thus, it provides a favorable financial environment for small and medium enterprises and eases the pressure of financing difficulties of SMEs. This indicates that solving the problem of Macmillan Gap absolutely requires the government's support.

\section{Acknowledgement}

Fund project: 1 . The study of law-finance system arrangement about the folk financial docking "Macmillan Gap" (humanities and social science research project from education ministry, 15yjc790050); 2. Research on financial servicing Private economy development in Jilin province (JI Fit word of educational, scientific and cultural [2014] No. 131); 3. Building financial support system for science-technology enterprises in size of micro, small and medium in Jilin province (20140418024FG).

\section{References}

[1] Chuan-hui Geng. Analysis and countermeasure of financing of mid-and-small enterprises in Jilin province [J]. JOURNAL OF CHANGCHUN INSTITUTE OF TECHNOLOGY (SOCIAL SCIENCES EDITION), 2006.

[2] Xin Geng. Factors and Strategies of the Financing of Mid-and-small Enterprises in China [J]. INNER MONGOLIA SCIENCE TECHNOLY AND ECONOMY, 2004.

[3] Feng-ge Cui, Bing Liu \& Chi Zhang. Research on the Unstable Financing of SMEs Based on the Prudent Monetary Policy [J]. Industrial Technology \& Economy, 2013.

[4] Ming Cui. Research on the Technology Innovation of SMEs in Jilin Province [J]. Journal of Jilin Province Economic Management Cadre College, 2015, 10.

[5] Hui-ping Zhang. Financial Measures of Resolving Financing Difficulties of SMEs in Jilin [J]. Taxation and Economy, 2015.

[6] Zhi-peng Cao. Relationship Lending and Financing of SMEs in China [J]. Finance and Economy, 2013.

[7] Shi-mei Jiang. Research on the Financing of SMEs in China [J]. Economic Vision, 2014.

[8] Zuo-wei Zhu. Problems and Countermeasures in Financial Management of SMEs [J]. Economic \& Trade, 2015.

[9] Hua Chen. Analysis of the Present Financing Situation of Private Credit Enterprises and Discussion on Its Standardized Approaches [J]. Chinese and Foreign Entrepreneurs, 2014.

[10] Xiao-yu Wang. The Analysis of Macmillan Gap and Chinese Way of Management [J]. Journal of Southern Yangtze University:Humanities \& Social Sciences Edition, 2011. 
[11] Zhi-qian Hui. Research on the Problems of Financing of SMEs in China [J]. Zhishi Jingji, 2015.

[12] Bo-xian Lin. Research on the Present Development Situation of Domestic Folk Credit and Its influences [J]. China Economist, 2013.

[13] Xia Wu. Effective Financing [M]. Beijing: Economy Press • China, 2012. 